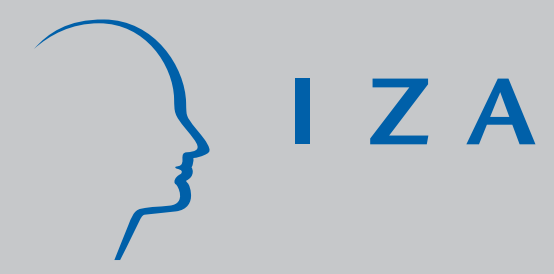

IZA DP No. 3610

Weight Gain in Adolescents and Their Peers

Timothy J . Halliday

Sally Kwak

July 2008

Forschungsinstitut

zur Zukunft der Arbeit

Institute for the Study

of Labor 


\title{
Weight Gain in Adolescents and Their Peers
}

\author{
Timothy J. Halliday \\ University of Hawaii at Manoa \\ and IZA \\ Sally Kwak \\ University of Hawaii at Manoa
}

\author{
Discussion Paper No. 3610 \\ July 2008
}

\author{
IZA \\ P.O. Box 7240 \\ 53072 Bonn \\ Germany \\ Phone: +49-228-3894-0 \\ Fax: +49-228-3894-180 \\ E-mail: iza@iza.org
}

Any opinions expressed here are those of the author(s) and not those of IZA. Research published in this series may include views on policy, but the institute itself takes no institutional policy positions.

The Institute for the Study of Labor (IZA) in Bonn is a local and virtual international research center and a place of communication between science, politics and business. IZA is an independent nonprofit organization supported by Deutsche Post World Net. The center is associated with the University of Bonn and offers a stimulating research environment through its international network, workshops and conferences, data service, project support, research visits and doctoral program. IZA engages in (i) original and internationally competitive research in all fields of labor economics, (ii) development of policy concepts, and (iii) dissemination of research results and concepts to the interested public.

IZA Discussion Papers often represent preliminary work and are circulated to encourage discussion. Citation of such a paper should account for its provisional character. A revised version may be available directly from the author. 
IZA Discussion Paper No. 3610

July 2008

\section{ABSTRACT \\ Weight Gain in Adolescents and Their Peers}

Despite the urgent public health implications, relatively little is yet known about the effect of peers on adolescent weight gain. We describe trends and features of adolescent BMI in a nationally representative dataset and document correlations in weight gain among peers. We find strong correlations between own body mass index (BMI) and peers' BMI's. Though the correlations are especially strong in the upper ends of the BMI distribution, the relationship is smooth and holds over almost the entire range of adolescent BMI. Furthermore, the results are robust to the inclusion of school fixed effects and basic controls for other confounding factors such as race, sex, and age. Some recent research in this area asks whether or not adolescent weight gain is caused by peers. We discuss the econometric difficulties in plausibly estimating such effects. Our results do not rule out the existence of these types of social network effects.

JEL Classification: $\quad 110, I 12$

Keywords: $\quad$ obesity, peer effects, adolescent health

Corresponding author:

Timothy J. Halliday

Department of Economics

University of Hawai'i at Manoa

2424 Maile Way

Saunders Hall 533

Honolulu, HI 96822

USA

E-mail: halliday@hawaii.edu

*We would like to thank Patricia Anderson for comments on an earlier draft. 


\section{Introduction}

Since the 1960's, obesity rates among children in the United States have risen dramatically. The Centers for Disease Control and Prevention (CDC) reports that while fewer than five percent of children ages six through eleven were considered obese in 1963, over 15 percent are considered obese today. In adolescents ages 12 through 19, similar trends hold; obesity rates for this group were just under five percent in 1966 and are well over 15 percent today. Rates of overweight have increased for all groups of children, for both boys and girls and across all ages and races. In addition, the rate at which children gain weight as they grow older has increased over time (Anderson et al, 2003). Researchers are particularly interested in pinpointing the causes of this trend because of the steep costs associated with it. Obesity puts children at risk for a myriad of physical diseases such as cardiovascular disease, type 2 diabetes, hypertension, dyslipidemia, sleep apnea, menstrual abnormalities, and osteoarthritis, as well as emotional problems such as depression, social marginalization, and low self-esteem. Furthermore, obese children often grow up to be obese adults. Economic estimates of the cost of the overall obesity epidemic in the United States currently range in the billions of dollars ${ }^{1}$ and will likely continue to rise.

Relatively little is known about the root causes of the current increase in obesity rates in children and the effectiveness of various school and home-based policy interventions. Clearly, eating more calories and exercising less leads to weight gain. Less obvious are the causes behind the growing propensity of children to eat more and exercise less. Researchers commonly attribute current trends in obesity rates to genetics, television viewing habits, increases in availability and cost of fast food, among others. In addition, economists have investigated the potential relationship

\footnotetext{
${ }^{1}$ See for example, http://www.cnn.com/2004/HEALTH/conditions/01/21/obesity.spending.ap/; http://www.forbes.com/2006/07/19/obesity-fat-costs cx mh 0720obesity.html; http://www.usatoday.com/news/health/2002-01-21-obesity.htm; http://www.cdc.gov/nccdphp/dnpa/obesity/economic consequences.htm.
} 
between rising obesity rates and mother's labor supply (Anderson et al, 2003), problems in school finance and accompanying soft drink and snack vending contracts (Anderson et al, 2003), the national school lunch program (Whitmore, 2008), and improvements in technology that lower the time price of food (Lakdawalla and Philipson, 2002; Cutler et al, 2003).

A recent study in the New England Journal of Medicine (NEJM) explores another possible factor in rising obesity rates, the effect of peers on weight gain (Christakis and Fowler, 2007). Researchers use data from the Framingham Heart Study to show that overweight and obese adults in Framingham, Massachusetts tend to cluster together socially. Using this evidence, the authors argue for the existence of endogenous peer effects in the spread of obesity. The existence (or not) of peer effects in rising obesity rates is important for policy. If gaining weight causes one's friends to be fat, policy interventions intended to reduce obesity rates affect targeted subjects as well as their friends. In the absence of such peer effects, policy interventions do not have these multiplier effects. Two additional papers explore the relationship between adolescent weight gain and the weight gain of peers. Cohen-Cole and Fletcher (2008) refute the existence of peer effects in weight gain among adolescents while Trogdon, Nonnemaker, and Pais (2008) find significant peer effects mainly among girls and among adolescents with high body mass indexes ${ }^{2}$ (BMI).

In this paper, we document and describe some trends and features of adolescent BMI and document correlations in weight gain among peers. We show that own BMI is strongly correlated with peers' BMI's. And though we can wipe out this correlation by including individual fixed effects in the spirit of Cohen-Cole and Fletcher (2008), we do not believe this necessarily indicates a lack of correlation (Deaton, 1995). (A discussion of this point follows in Section IV.) These correlations are especially strong in the upper end of the BMI distribution but the relationship is smooth and holds over almost the entire range of adolescent BMI. Furthermore, the results are robust to the

\footnotetext{
${ }^{2} \mathrm{BMI}$ is a commonly used measure of weight in the obesity literature. It is an index that measures weight in kilograms normalized by height in meters.
} 
inclusion of school fixed effects and basic controls for other confounding factors such as race, sex, and age. The effect is strong for girls relative to boys, and the correlations are especially strong between girls and their female friends. Neither we nor the papers mentioned previously, are able to satisfactorily solve some of the important empirical problems in estimating unbiased causal peer effects. Though we are unable to precisely identify causal effects of peer weight gain on own weight gain among adolescents, we discuss implications of our results for the peer effects literature. We show that the correlations found among the adults in the NEJM study can be replicated in our sample of adolescents. And we discuss whether or not these results can reasonably be construed as evidence of endogenous peer effects.

The main contributions of the paper are twofold. First, we replicate the correlations between own and peer weight in Christakis and Fowler (2007) on a sample of adolescents and then show we can wipe these correlations out by including individual fixed effects in the spirit of CohenCole and Fletcher (2008). Second, we discuss the difficulties in empirically identifying causal peer effects in weight gain and instead present a careful and thorough set of descriptive results documenting features of adolescent BMI and their relationship to peer BMI. We are also the first (as far as we are aware) to discuss the unique issues in assessing adolescent (as opposed to adult) weight gain and to use the CDC definitions of 'overweight', 'underweight' and 'obese' in our analyses rather than the traditional definitions used for adult weight gain. The remainder of the paper is organized as follows: We describe our data in section II, including a discussion of our construction of the peer group variables. In section III, we discuss our methods and in section IV we present our empirical findings. Section V concludes.

\section{Data}


In this study, we use data from the National Longitudinal Adolescent Health Survey (Add Health). The Add Health survey was conducted by the Carolina Population Center and is available for a nationally representative sample of students who were in seventh through twelfth grades in 1994. Wave I, which was fielded in 1994-1995, consists of an In-School questionnaire that was filled out by 90,118 students in 145 schools in 80 communities. A subset of 20,745 students was then chosen for an in-depth In-Home survey. Wave II, which was fielded in 1996, includes an In-Home questionnaire that was completed by 14,738 students, a subset of the original 20,745 Wave I pupils. The 145 schools in the Wave I survey consist of pairs of sister schools. That is, if a particular high school was included in the survey, the corresponding feeder junior high or middle school was also included. If a school spanning seventh through twelfth grades was chosen for the survey, no sister school was included. In this study, the full dataset consists of 14, 738 students who were surveyed In-Home in both Wave I and Wave II. We include in our sample those students who have full information on height and weight and who have at least one friend with full information on height and weight. Table 1A presents some basic summary statistics for our sample and for the full sample.

\section{Body Mass Index}

Students who were selected for the In-Home survey were asked for information on height and weight in Wave I and again in Wave II. Using this information, we construct a Body Mass Index (BMI) variable according to the formula: $\mathrm{BMI}=703 * \frac{\text { weight }}{\text { height }^{2}} \cdot{ }^{3}$ 'Overweight' and 'obese' are generally defined to be 'greater than $\mathrm{BMI}=25$ ' and 'greater than $\mathrm{BMI}=30$ ', respectively. However, the medical literature defines these thresholds differently for children and adolescents. Following this convention, we use BMI measures to construct two additional variables: "over weight" which

\footnotetext{
${ }^{3} \mathrm{BMI}$ is calculated as weight in kilograms normalized by height in meters. Because height and weight in the Add Health survey are recorded in inches and pounds, we use a conversion factor of 703 .
} 
we define to be above the $90^{\text {th }}$ percentile of BMI for the appropriate age-sex group and "under weight" which corresponds to being below the $10^{\text {th }}$ percentile of BMI for the appropriate age-sex group. The exact percentiles are derived from age and sex specific distributions; we use the distributions given in the 2000 CDC Growth Charts. These alternative cut-off points account for the growth spurts children experience in adolescence.

Figures $1 \mathrm{~A}$ and $1 \mathrm{~B}$ display the distribution of $\mathrm{BMI}$ for males and females in our sample. It is interesting to note that while BMI tends to be concentrated in the low twenties, there are substantial numbers of adolescents with BMI's above 25; the densities for both girls and boys exhibit fat upper tails. This is especially striking since BMI percentile cutoff points for whether or not an individual is considered overweight or obese increase with age for adolescents (see Appendix). For example, a 15 year old boy with a BMI of 23 is considered overweight, but a 21 year old man with the same BMI is not. Thus, the high number of adolescents with BMI's in the upper tail of the distribution is even more worrisome than it would be in a sample of adults. Using adult definitions of overweight and obese in this setting will cause us to significantly underestimate the rates of overweight and obese adolescents in our sample.

Table $1 \mathrm{~B}$ shows that average $\mathrm{BMI}$ in the overall sample is 22.75 . In addition, approximately 23 percent of the sample has BMI over 25 in the base year. BMI's vary quite significantly for boys and girls. For example, 25 percent of boys have BMI's above 25 while only 20 percent of girls are similarly classified. However, both boys and girls become overweight at the same rate; three percent of both boys and girls move from having a BMI of less than 25 to having a BMI of greater than 25 between the base year and the follow-up year. Thus, our data confirm recent worries that obesity and overly high BMI is a major health concern among adolescents.

Self-Reported Health Status 
In addition to measures of BMI, we also examine measures of self-reported health status. The measure of self-reported health status in the survey is a categorical variable. It takes on the value 1 if the student rates his own health as 'excellent', 2 if 'very good', 3 if 'good', 4 if 'fair', 5 if 'poor'. Despite the problems associated with self-reporting and with the use of categorical, qualitative measures of health, there is some strong evidence in the existing literature that selfreported health status is a reliable measure of actual health status (see for example, Deaton and Paxson, 1998). We examine the relationship between self-reported health status and BMI. Figure 2 plots three kernel regressions of self-reported health status on BMI: one for the full sample, another for boys in the sample, and finally for girls in the sample. In all cases, the relationship is upward sloping and quite smooth. In other words, BMI and self-reported health status move together so that as BMI increases, the health of the individual worsens.

In Table 2 we create a binary indicator variable for self-reported bad health and run probit regressions. The results show correlations between self-reported bad health and BMI. We find that these are strongly positive, significant, remarkably stable and robust to inclusion of controls for sex, race, and socioeconomic status as measured by parental education. Though we conduct the remaining analysis for measures of overweight and BMI, these demonstrated correlations between adolescent BMI and self-reported health status suggest that our analysis has implications for not just weight but overall health.

\section{Adolescent Growth Spurts}

Because of the rapid changes in height and weight accompanying adolescent growth spurts, the task of identifying causal peer effects in weight gain is more complicated than in adults. Figure 3 illustrates a strictly down-ward sloping relationship between change in BMI and change in height. In other words, those adolescents who experience the largest drops in BMI are also those who grow 
the most in height. Similarly, those who gain in BMI are those who see little or no change in height. To account for some of these differences, we use the CDC definitions of 'overweight', 'underweight' and 'obese' in our analyses rather than the traditional definitions used for adult weight gain. These traditional definitions define 'obese' as having BMI $>30$, 'overweight' as having $\mathrm{BMI}>25$, and 'underweight' as having $\mathrm{BMI}<18.5$. However, because body fat changes significantly as children and adolescents grow, the CDC recommends using percentiles for age and sex to determine whether or not an adolescent is obese, overweight or underweight.

The larger issue is that analyses of correlations between own and peer weight fluctuations in adolescents are confounded by growth spurts. Since changes in height are not driven by behavioral choices, we must be especially careful with causal interpretations of correlations in own and peer weight changes for adolescents.

\section{Peer Networks}

The Add Health survey is well-suited to our purposes because of the extensive data on friendship networks. In each of the surveys, students are asked to nominate five female friends and five male friends. In almost all cases, students report fewer than five male and five female friends indicating that they are not constrained in their choice of friends in their network by the ten-friend limit. The average number of friends nominated by individuals in our sample is 2.10 (with a standard deviation of 1.76). These friend nominations include both friends in the same school as well as friends from outside of school. Because we do not have information on friends outside of the respondent's school, we are unable to include them in our measure of average peer group BMI. However, the vast majority of friend nominations (approximately 85\%) are to other students in the same school. There are a sizeable number of nominations to friends that are not found on the 
school rosters. This may be due to nicknames not matching official names, students who are new to the school, or errors in the school records.

As discussed in Halliday and Kwak (2008) and Manski (1995), definitions of the peer network in the peer effects literature are often arbitrary. Manski notes that "Researchers studying social effects rarely offer empirical evidence to support their specifications of reference groups" (1995). Because the Add Health dataset includes information on self-nominated friends, we do not have to resort to the usual ad-hoc specification of peer groups. Our construction of peer groups uses information from the Add Health friendship network to derive average levels of BMI across self-nominated friends. This definition only includes friends directly nominated by the respondent and is limited to at most five male and five female friends.

\section{Methods}

We begin with a standard estimation equation in the peer effects literature:

$$
y_{\text {ist }}=\bar{y}_{\text {ist }} \beta+x_{i s} \lambda+\delta_{s}+\alpha_{i}+\varepsilon_{\text {ist }}
$$

where $y_{\text {ist }}$ is either BMI or some function of it for pupil $i$ in school $s$ at time $t, \bar{y}_{\text {ist }}$ is the average of $y_{i s t}$ in the peer network, $x_{i s}$ is a vector of controls, $\alpha_{i}$ is an individual fixed effect and $\delta_{s}$ is a school dummy. The parameter $\beta$ is a measure of endogenous peer effects. Of course, as has been discussed by Manski (1995) and others, OLS estimation of this model will not identify $\beta$ for two primary reasons. First, in the presence of endogenous effects, average obesity in the network is an equilibrium outcome and as a result, the residual in the equation is correlated with $\bar{y}_{\text {ist }}$. In the literature, this is referred to as the "reflection problem." Second, because pupils tend to choose friends with similar characteristics that are also correlated with behavior, there are apt to be omitted variables in the residual that are correlated with both own and peer obesity. Manksi (1995) refers to 
this source of bias as "correlated effects." Inclusion of the vector $x_{i s}$ and the individual and school fixed effects should mitigate, but not necessarily eliminate, this source of bias.

To address these concerns, the standard approach in the literature is to look for a source of variation in peer behavior and then argue that this variation is exogenous. For example, one commonly used technique is to assume that certain background characteristics of the peer group do not enter the structural model and to use these variables as instruments (see Gavrira and Raphael 2001 and Halliday and Kwak 2008, for example). When examining obesity, however, these types of instruments are very weak because the relationship between obesity and background characteristics is confounded by biology. It is also more difficult than usual to defend the needed exclusion restrictions. Therefore, we employ fixed effects techniques instead. This approach has been used previously by Arcidiacono and Nicholson (2005), but unfortunately does not adequately solve the reflection problem. Because we are unable to adequately solve the reflection problem, we are unable to provide unbiased estimates of the causal effect of peers on adolescents' weight gain or loss. In the absence of bias due to measurement error, this inability to solve the reflection problem leads to upper bounds on the true endogenous effect. In addition, if the use of fixed effects only mitigates but does not fully account for correlated effects, the estimates will be further biased upwards.

Without credible estimates of an endogenous peer effect, we focus instead on the correlations in BMI between adolescents and their self-nominated peers. The fixed effects method allows us to view these correlations while controlling for a variety of potentially confounding factors. In the following section, we examine these correlations at various percentiles of the BMI distribution; for overweight and underweight adolescents; and for boys and girls. We also discuss two plausible stories behind the correlations we find.

\footnotetext{
4 There are other sources of bias as well. One source is that own behavior is positively correlated with the background characteristics of the peer group. Manski (1995) refers to these as "contextual effects." Another is that either the behavior within the group is poorly measured or that the definition of the peer group is a poor approximation of the true peer group. See Halliday and Kwak (2008) for a more thorough discussion of this source of bias.
} 


\section{Results}

Our main results are presented in Table 3. We estimate models for three different dependent variables: BMI, whether overweight or not, and whether underweight or not. In all three cases, we include controls for gender, grade, race, and health status as well as a school or individual fixed effect. Sample sizes for the regressions are smaller than the full sample because there is a substantial amount of missing information in the Add Health data. For example, many nominated friends can not be located in the data and often height and weight are not reported in one or both years of the survey. In addition, there are sizeable numbers of missing observations for selfreported health status, race, gender, and grade. The school fixed effects regressions include control variables for race and health status and are thus substantially smaller than the individual fixed effects regressions which do not separately control for these factors. Reassuringly, the sample sizes are comparable to those in Cohen-Cole and Fletcher (2008) which also uses the Add Health data.

Overall, we see that overweight adolescents do tend to associate with one another. Column 1 of Table 3 presents school fixed effects results for BMI and column 3 presents results for the propensity to be overweight. Both sets of results show significant correlations between the average rates of overweight among friends and an adolescent's own weight. On average, an increase of one point in the average friend BMI is associated with a 0.19 point increase in an adolescent's BMI. For a 5'9" 150 pound boy with 5'9" friends each weighing 150 pounds, this means an increase of seven pounds in average friends' weight is associated with an increase of about two pounds in own weight. Similarly, an increase of 10 percentage points in friends' propensity to be overweight is associated with a 1.1 percentage point increase in own propensity to be overweight.

Christakis and Fowler (2007) conduct a similar analysis for adults and find similar results. They conclude that fat adults cause each other to be fat. However, we caution against interpreting 
the results in this way. As discussed in section III, the two main sources of bias in estimating endogenous peer effects are correlated effects and the reflection problem. By including fixed effects in our regressions, we attempt to address the problem of correlated effects. However, neither our study nor the NEJM study solves the reflection problem. The unsolved reflection problem biases estimates upward and we can not rule out the absence of significant peer effects even if our regression estimates are positive and significant. Thus, neither our results nor those of the NEJM study can differentiate between a causal effect of peers on weight gain and a story in which overweight adolescents choose overweight friends because they are socially ostracized by their slimmer peers. Both scenarios are equally consistent with the results.

Whichever story is correct, we nonetheless see that the tendency of overweight students to associate with overweight peers is strong. It is robust to using different definitions of weight as the dependent variable and also holds for male and female sub-samples. Figure 4 shows kernel regression estimates of own BMI on average peer group BMI. The figures show a strong positive correlation between own and peer BMI for both girls and boys. Furthermore, the estimates for girls are stronger than for boys. This indicates that one of two stories holds: either fat girls are more likely to be ostracized by their thinner peers than fat boys, or girls are more likely than boys to become fat as a result of having fat friends. These results are consistent with the regression results presented in Table 3. Interestingly, we see that these correlations disappear for underweight peers (see Table 4, Column 5) indicating that underweight adolescents do not associate with primarily underweight friends. If we observe the correlations in columns 1 and 3 of Table 4 because slim adolescents choose not to be friends with their overweight classmates and not because overweight students cause their friends to be overweight, the lack of significant correlations in column 5 are consistent with the social ostracism that accompanies being overweight but not underweight. If, on the other hand, the clustering of overweight individuals with overweight friends is brought on by a 
causal effect of peers on weight gain, the lack of correlations among underweight individuals may be explained by the difficulties in losing weight relative to the ease of gaining weight. In either case, the weaker or non-existent correlations among underweight individuals are of particular note in light of the suspected contagion effects in eating disorders such as anorexia among adolescents. The lack of correlation between underweight adolescents with underweight friends suggests that the contagion effects of eating disorders such as anorexia (if they do indeed exist) occur through channels other than friendship networks.

Notably, the significant correlations among overweight adolescents in Table 3 disappear when we include individual fixed effects methods in the spirit of Cohen-Cole and Fletcher (2008). The estimates in columns 2 and 4 drop to zero. In general, it is likely that individual fixed effects more effectively eliminate the omitted correlated effects in the residuals than do the school fixed effects. However, we also unfortunately eliminate much of the variation in BMI by controlling for individual fixed effects. As discussed in Deaton (1995), addressing omitted variables bias in fixedeffects regressions come with many costs including: loss of observations, reducing variation in the right-hand side variables and exacerbating the attenuation bias of white noise measurement error. Due to these reasons, we maintain that the individual fixed effects estimator is likely not efficient in this setting and the lack of significant correlations between own and peer BMI in these regressions neither support nor refute an actual lack of correlation between the two variables. We find the individual fixed effects results inconclusive.

Next we estimate the models with school fixed effects separately by gender. Interestingly, the data exhibit some differences in correlations between boys and girls. The girls' BMI measures are strongly associated with that of their female friends (Table 4, Column 2, Row 2) while boys' measures are less strongly associated with their male friends (point estimates are 0.18 versus 0.30 for girls). This pattern of results holds for binary measures of overweight as well (Table 4, Columns 3 
and 4). These results are also consistent with the kernel regressions in Figure 4. We clearly see that the correlations between own and peer weight are stronger for girls than for boys.

Table 5 investigates further the determinants of changes in weight. The estimates measure correlations between change in own BMI and the level of peer BMI, change in own height, and baseline level of own BMI while controlling for race, school, gender, age, health status, and parental background information. In row 1, we see that again girls exhibit the largest correlations between own and peer BMI measures. More specifically, the girls who gain the most weight are also those who have fatter than average friends. This relationship is much weaker in boys. Consistent with Figure 3, row 2 of Table 5 also shows that a significant determinant of change in BMI is change in height. Figure 5 shows that there is significant variation in change in BMI across our study years. However, Table 5 shows that a large portion of this variation may be explained by changes in height and not changes in weight. This further confirms the danger of interpreting any correlations in own and peer BMI as a behavioral social network effect.

In Table 6 we examine the correlations between own and peer BMI looking at various cutoff points in the BMI distribution. We see that correlations follow a smooth pattern and that there are no anomalous discontinuities in these correlations at any particular points in the weight distribution. For example, column 1 shows a strong association of own BMI and the peer group's propensity to exceed the $90^{\text {th }}$ percentile of the overall weight distribution. Columns 3 and 5 show this correlation continues to be significant at the $85^{\text {th }}$ percentile cutoff and the $75^{\text {th }}$ percentile cutoff, though the size of the correlation diminishes monotonically. As with the main results in Table 3 , there is no association between own BMI and the lower end of the peer group BMI distribution. Table 7 repeats Table 6 using a dummy variable of whether this individual is overweight or not. The results in Table 7 repeat the pattern of results in Table 6 and provide a useful robustness check. 


\section{Conclusions}

We conclude that there is a tendency for students with high levels of BMI to cluster within peer networks. Due to problems with weak instruments in instrumental variables estimates, we rely on fixed effects models to control for various correlated and contextual effects. When school fixed effects are included in the models, we do find positive and significant estimates, but concerns about omitted correlated effects and the reflection problem suggest that these are biased estimates of the true causal effect, if any exists. In the absence of measurement error, these estimates are upper bounds of the true causal effect and so we cannot rule out either positive or zero estimates. When individual fixed effects are included, the effects disappear entirely. However, this is due to the lack of efficiency of this estimator in this setting and cannot necessarily be interpreted as evidence of a zero effect. Given the inability to satisfactorily solve the omitted correlated effects and the reflection problem, the results presented are consistent with two possible stories: first, overweight adolescents sort themselves into networks with other overweight friends or second, overweight adolescents influence their friends to also become overweight. Our study carefully documents the correlations in a nationally representative sample of adolescents. However, neither our study nor the three that precede ours can differentiate between these two explanations. 


\section{References}

Anderson, Patricia, Kristin Butcher and Phillip Levine, (2003). Economic Perspectives on Childhood Obesity," Economic Perspectives, 3Q, 30 - 48.

Anderson, Patricia, Kristin Butcher and Phillip Levine, (2003). "Maternal Employment and Overweight Children,” Journal of Health Economics, 22, 477 - 504.

Anderson, Patricia and Kristin Butcher, (2006). "Causes of the Increase in Childhood Overweight and Obesity," Future of Children, 16: 19 -45.

Arcidiacono, Peter and Sean Nicholson, (2005). "Peer effects in medical school," Journal of Public Economics, 89: 327-350.

Christakis, Nicholas A. and James H. Fowler, (2007). "The Spread of Obesity in a Large Social Network over 32 Years," New England Journal of Medicine, 357: 370-9.

Cohen-Cole, Ethan and Jason Fletcher, (2008). "Is Obesity Contagious? Social Networks versus Environmental Factors in the Obesity Epidemic," forthcoming Journal of Health Economics.

Cutler, David, Edward Glaeser, and Jesse Shapiro, (2003). "Why Have Americans Become More Obese?" Journal of Economic Perspectives, 17(3): 93-118.

Deaton, Angus, (1995). "Data and Econometric Tools for Development Analysis" in Handbook of Development Economics, Volume 3 A, Jere Behrman and T.N. Srinivasan, ed., North-Holland Press.

Deaton, Angus and Christina Paxson, (1998). "Health, Income, and Inequality over the Life Cycle" in Frontiers in the Economics of Aging, David A. Wise, ed., University of Chicago Press.

Halliday, Timothy and Sally Kwak, (2008). "What is a Peer? The Role of Peer Group Definition in the Estimation of Peer Effects," IZA Discussion Paper No. 3335.

Gaviria, Alejandro and Steven Raphael, (2001)."School-Based Peer Effects and Juvenile Behavior," Review of Economics and Statistics, 83: 257-268.

Lakdawalla, Darius and Tomas Philipson, (2003). "The Growth of Obesity and Technological Change: A Theoretical and Empirical Examination," NBER Working Paper W8946.

Manski, Charles F., (1995). Identification Problems in the Social Sciences. Cambridge, MA: Harvard University Press.

Trogdon, Jusin, James Nonnemaker, and Joanne Pail (2008). "Peer Effects in the Spread of Obesity," forthcoming Journal of Health Economics.

Whitmore, Diane (2008). "Does the Federal School Lunch Program Contribute to Childhood Obesity?" Harris School Working Paper \#05.13. 
Figure 1A. Distribution of BMI, Males

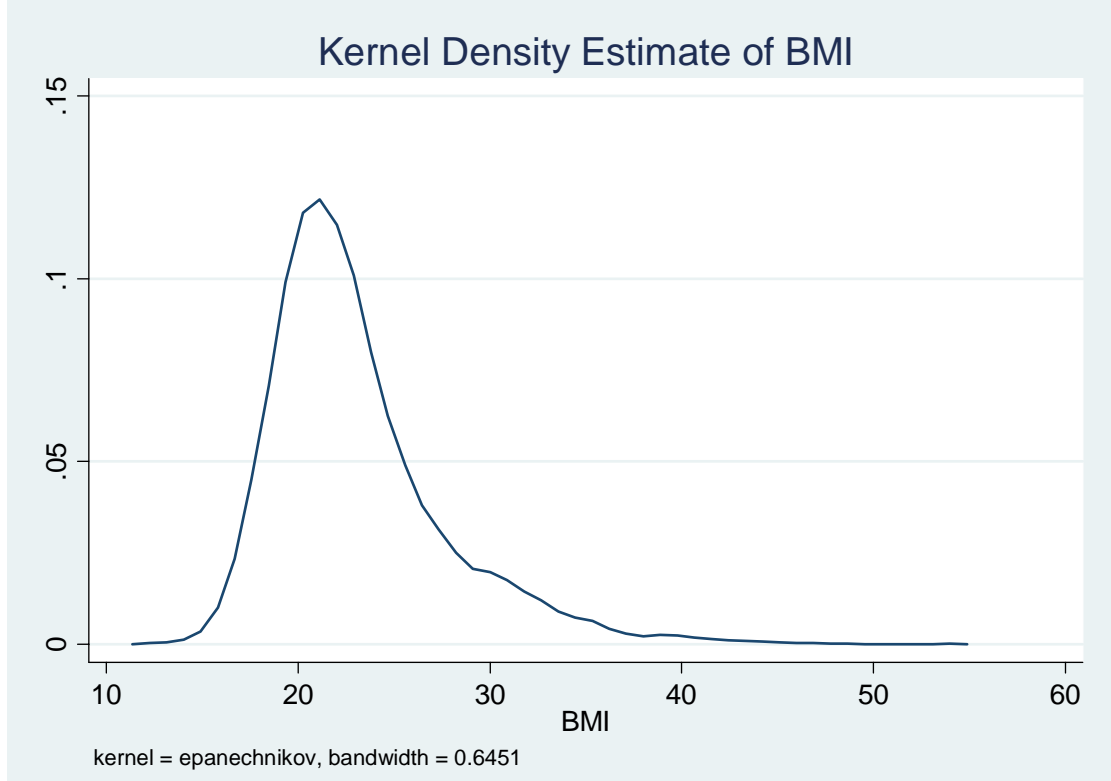

Figure 1B. Distribution of BMI, Females

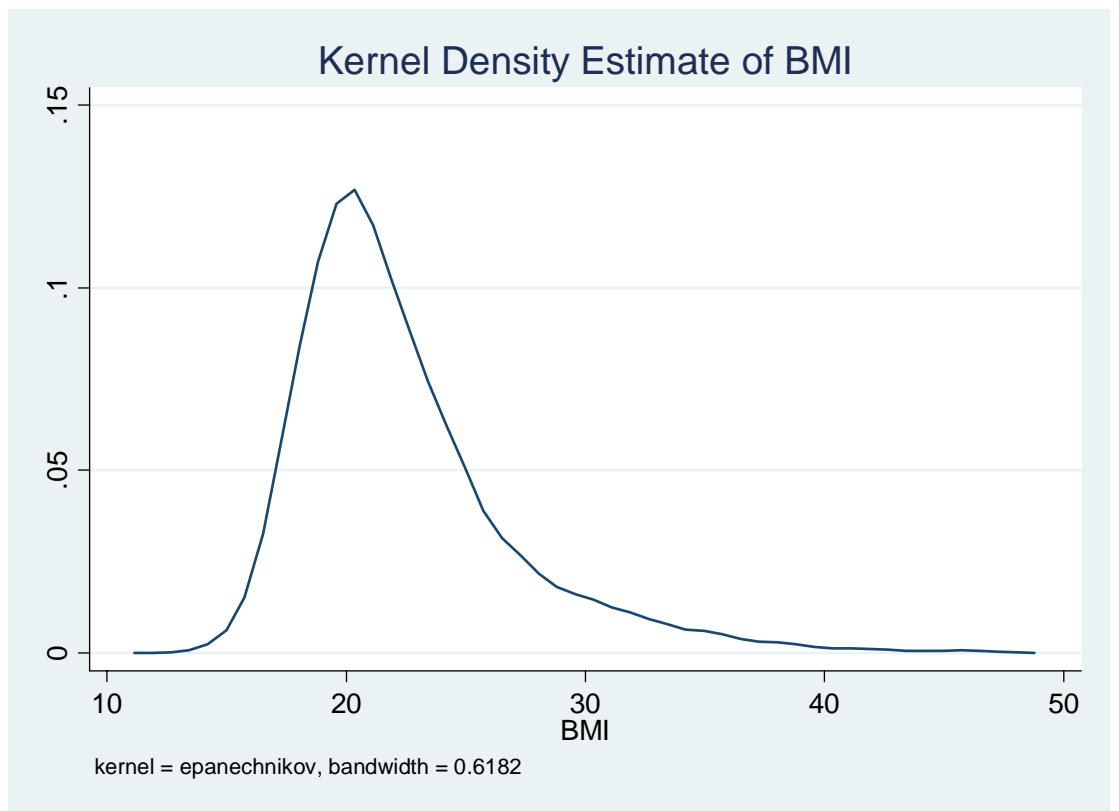


Figure 2. Kernel Regression of Self-Reported Health Status on BMI

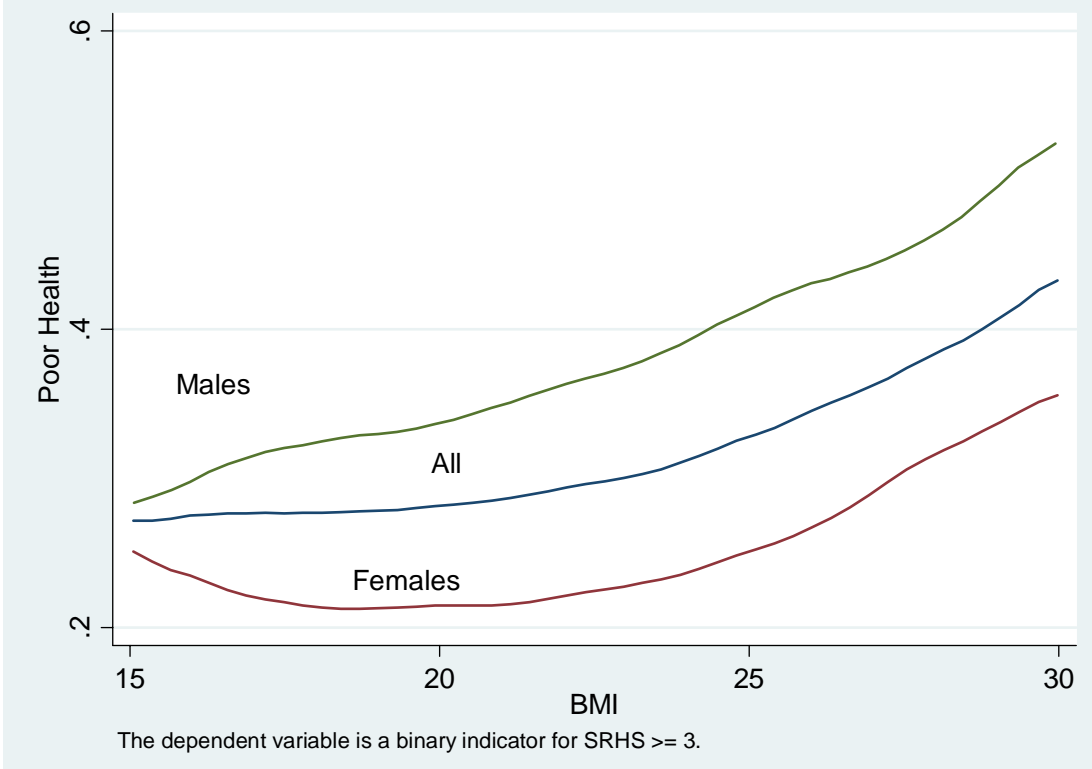


Figure 3. Relationship of BMI to Changes in Height

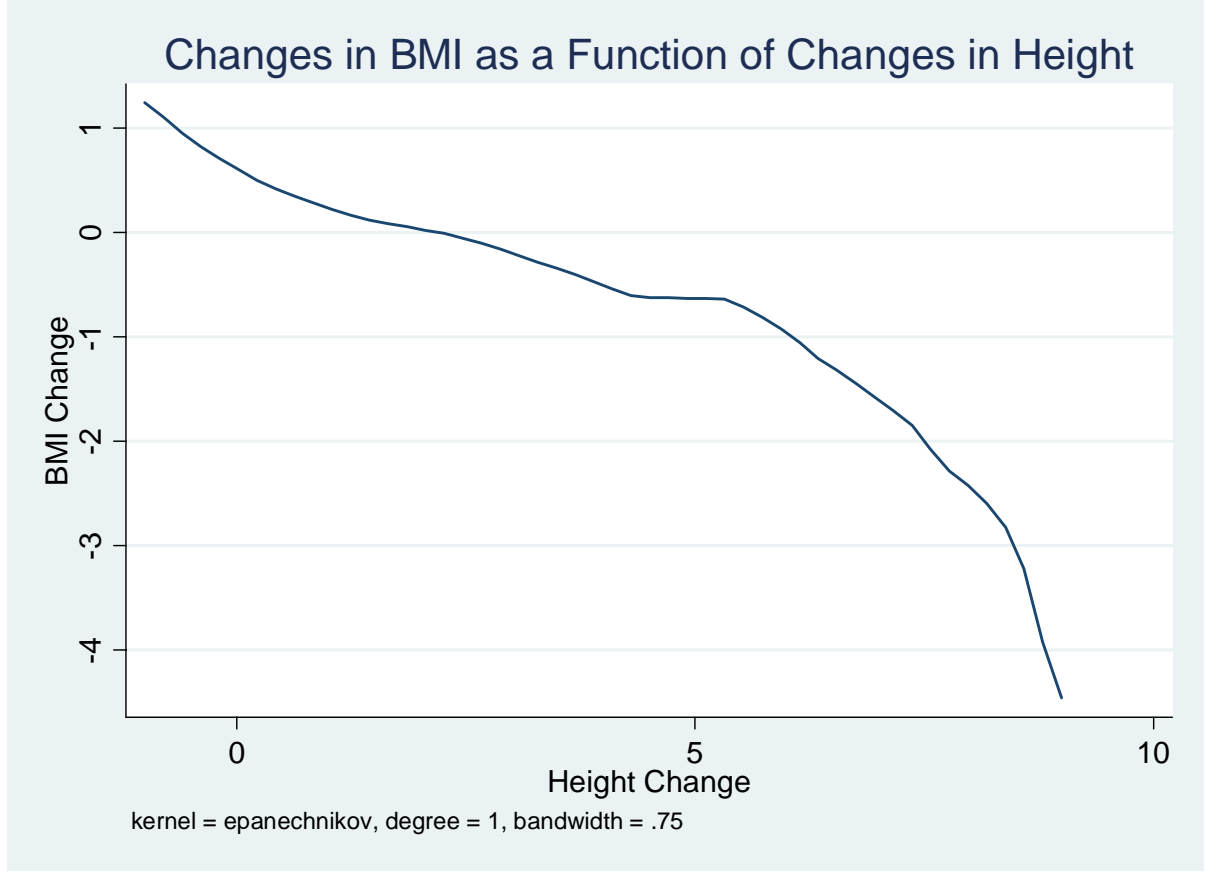

Figure 4. Kernel Regression Estimates of Own BMI on Average Peer Group BMI

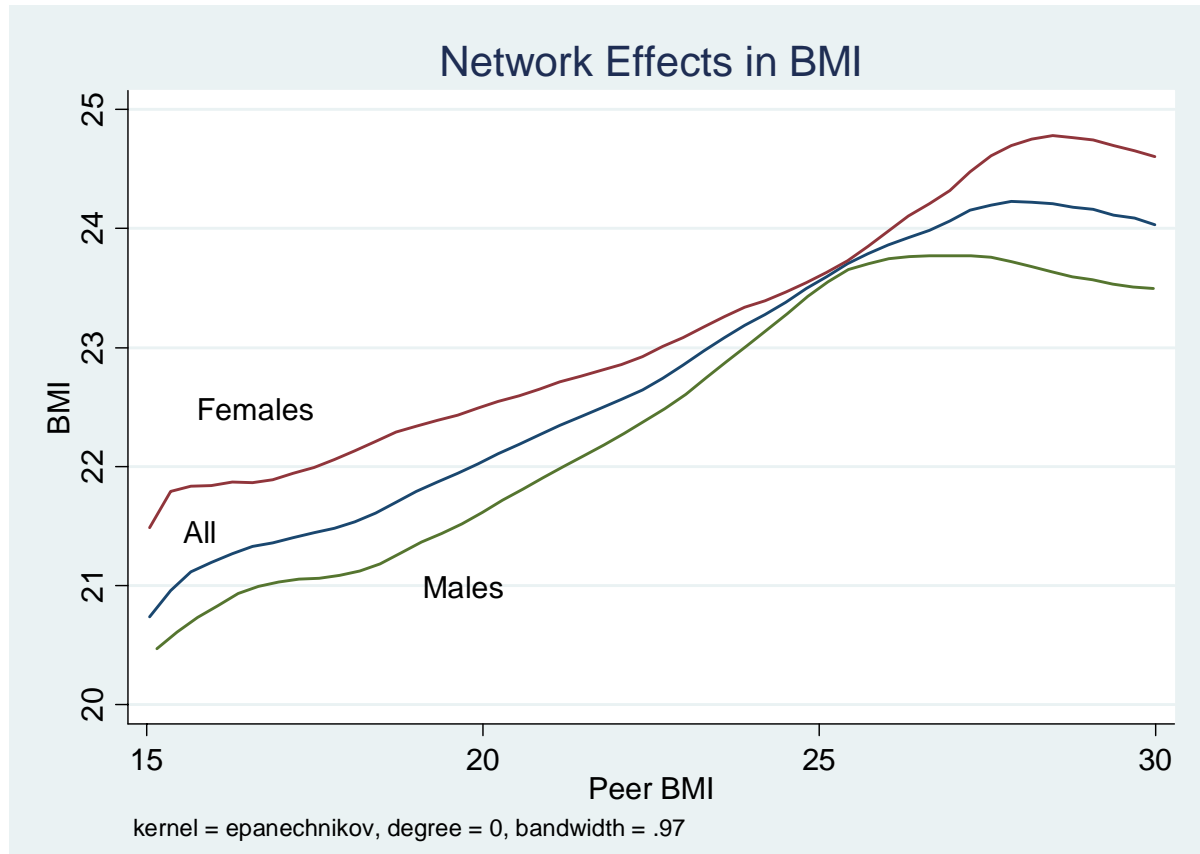


Figure 5. Distribution of Change in BMI Between Baseline and Follow-up Years

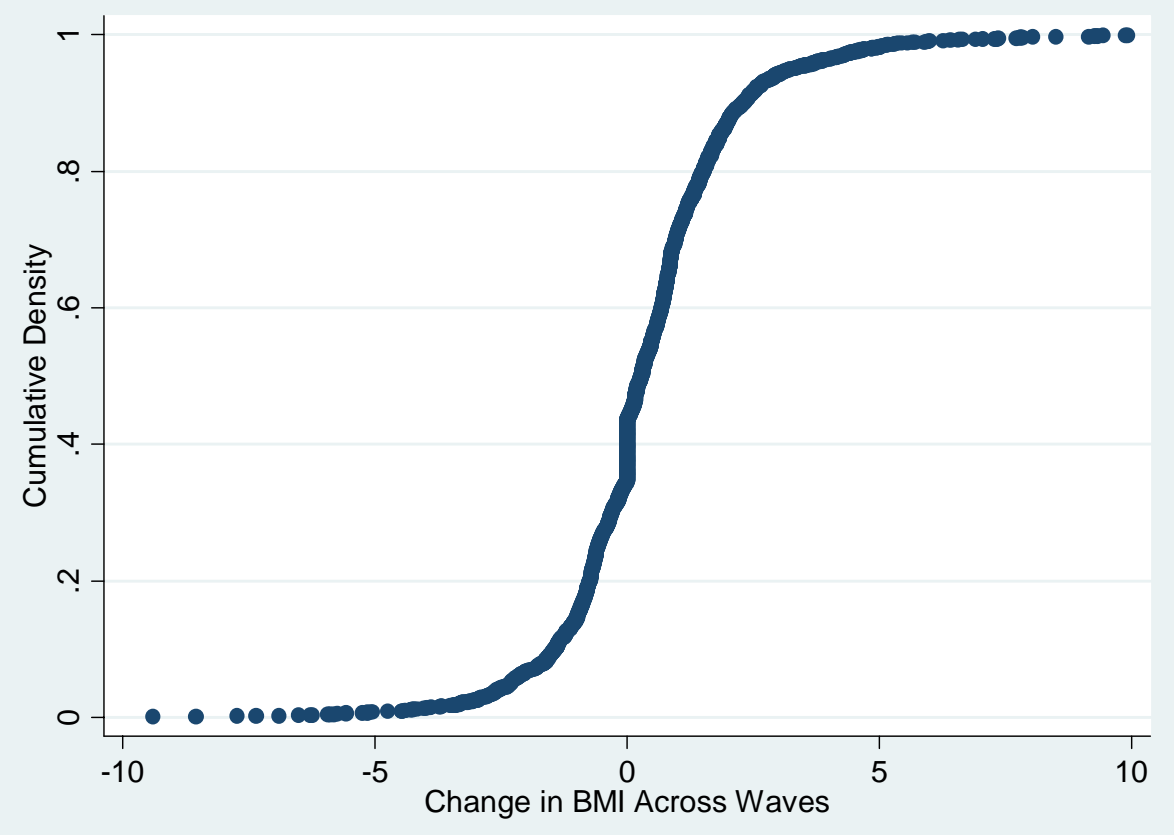


Table 1A: Baseline Characteristics

\begin{tabular}{lll}
\hline \hline Variable & Our Sub-Sample & Full Sample \\
\hline Age & 15.11 & 14.99 \\
& $(1.63)$ & $(1.72)$ \\
Male & .48 & 0.50 \\
& $(.50)$ & $(0.50)$ \\
Grade & 9.80 & 9.58 \\
& $(1.58)$ & $(1.62)$ \\
White & 0.55 & 0.61 \\
& $(.50)$ & $(0.49)$ \\
Black & 0.19 & 0.19 \\
& $(.39)$ & $(0.39)$ \\
Asian & 0.12 & 0.07 \\
& $(0.33)$ & $(0.26)$ \\
Self-Reported Health & 2.11 & 2.09 \\
Status & $(0.95)$ & $(0.94)$ \\
Mother Has a College & 0.34 & 0.32 \\
Degree & $(0.47)$ & $(0.47)$ \\
Father Has a College & 0.38 & 0.38 \\
Degree & $(0.49)$ & $(0.49)$ \\
\hline Stand deviation are repoted in &
\end{tabular}

Standard deviations are reported in parentheses.

${ }^{1}$ This is a categorical variable corresponding to the pupil's assessment of their own health $(1=$ excellent; 2 = very good; 3 = good; $4=$ fair; 5 = poor $)$. 
Table 1B: Summary Statistics for BMI

\begin{tabular}{|c|c|}
\hline Variable & $\begin{array}{l}\text { Mean } \\
\text { (Standard Deviation) }\end{array}$ \\
\hline \multicolumn{2}{|c|}{ All } \\
\hline BMI & $\begin{array}{l}22.75 \\
(4.58)\end{array}$ \\
\hline $\mathrm{BMI}>=25^{1}$ & 0.23 \\
\hline $\mathrm{BMI}<=18.5^{2}$ & $\begin{array}{l}(0.42) \\
0.12 \\
(0.33)\end{array}$ \\
\hline \multicolumn{2}{|c|}{ Male } \\
\hline BMI & $\begin{array}{l}23.09 \\
(4.62)\end{array}$ \\
\hline $\mathrm{BMI}>=25$ & $\begin{array}{l}0.25 \\
(0.43)\end{array}$ \\
\hline $\mathrm{BMI}<=18.5$ & $\begin{array}{l}0.10 \\
(0.30)\end{array}$ \\
\hline \multicolumn{2}{|c|}{ Females } \\
\hline BMI & $\begin{array}{l}22.40 \\
(4.59)\end{array}$ \\
\hline $\mathrm{BMI}>=25$ & $\begin{array}{l}0.20 \\
(0.40)\end{array}$ \\
\hline $\mathrm{BMI}<=18.5$ & $\begin{array}{l}0.15 \\
(0.36)\end{array}$ \\
\hline
\end{tabular}

${ }^{1}$ This is a binary variable indicating whether or not the respondent has BMI greater than or equal to 25.

${ }^{2}$ This is a binary variable indicating whether or not the respondent has BMI less than or equal to 18.5 . 
Table 2. Self-reported Health Status, BMI, and Socioeconomic Status

\begin{tabular}{|c|c|c|c|c|}
\hline & \multicolumn{4}{|c|}{ Dependent Variable: Self-Reported Health Status } \\
\hline BMI & $\begin{array}{c}(1) \\
0.016 \\
(10.79)\end{array}$ & $\begin{array}{c}(2) \\
0.018 \\
(10.60)\end{array}$ & $\begin{array}{c}(3) \\
0.018 \\
(10.92)\end{array}$ & $\begin{array}{c}(4) \\
0.015 \\
(8.23)\end{array}$ \\
\hline $\begin{array}{l}\text { Gender } \\
\text { Dummy } \\
(=1 \text { if male })\end{array}$ & - & $\begin{array}{c}-0.14 \\
(10.50)\end{array}$ & $\begin{array}{c}-0.14 \\
(-10.61)\end{array}$ & $\begin{array}{l}-0.14 \\
(-8.31)\end{array}$ \\
\hline $\begin{array}{l}\text { White Dummy } \\
\text { (=1 if White) }\end{array}$ & - & - & $\begin{array}{l}-0.07 \\
(-3.30)\end{array}$ & $\begin{array}{c}-0.05 \\
(-1.43)\end{array}$ \\
\hline $\begin{array}{l}\text { Black Dummy } \\
\text { (=1 if Black) }\end{array}$ & - & - & $\begin{array}{l}-0.09 \\
(-4.28)\end{array}$ & $\begin{array}{l}-0.07 \\
(-2.12)\end{array}$ \\
\hline $\begin{array}{l}\text { Asian Dummy } \\
(=1 \text { if Asian) }\end{array}$ & - & - & $\begin{array}{c}0.00 \\
(0.23)\end{array}$ & $\begin{array}{c}0.05 \\
(1.77)\end{array}$ \\
\hline $\begin{array}{l}\text { Mother's } \\
\text { Education }^{*}\end{array}$ & - & - & - & $\begin{array}{c}-0.03 \\
(-0.89)\end{array}$ \\
\hline $\begin{array}{l}\text { Father's } \\
\text { Education }^{*}\end{array}$ & - & - & - & $\begin{array}{l}-0.09 \\
(-5.15)\end{array}$ \\
\hline $\begin{array}{l}\mathrm{R} 2 \\
\mathrm{~N}\end{array}$ & $\begin{array}{c}0.0225 \\
4426\end{array}$ & $\begin{array}{c}0.0403 \\
4408\end{array}$ & $\begin{array}{c}0.0449 \\
4408\end{array}$ & $\begin{array}{c}0.0535 \\
2686\end{array}$ \\
\hline $\begin{array}{l}\text { Note: This table re } \\
\text { variable is a binary } \\
\text { parentheses. All st } \\
\text { complete set of gra } \\
\text { "These variables ard } \\
\text { degree. }\end{array}$ & $\begin{array}{l}\text { marginal } \\
\text { ator for SR } \\
\text { d errors ac } \\
\text { ammies. } \\
\text { ary variable }\end{array}$ & $\begin{array}{l}\text { ff a probi } \\
\text { ng good, } \\
\text { clusterin } \\
\text { ting that }\end{array}$ & $\begin{array}{l}\text { in which th } \\
\text { oor. Robus } \\
\text { hool. All res } \\
\text { her (father) }\end{array}$ & $\begin{array}{l}\text { ndent } \\
\text { istics are in } \\
\text { s include } \\
\text { ollege }\end{array}$ \\
\hline
\end{tabular}


Table 3. Correlations Between Own Weight and Peer Weight

\begin{tabular}{|c|c|c|c|c|c|c|}
\hline & \multicolumn{2}{|c|}{ BMI } & \multicolumn{2}{|c|}{ Overweight } & \multicolumn{2}{|c|}{ "Under Weight } \\
\hline & $(1)$ & (2) & (3) & (4) & (5) & (6) \\
\hline & School & Individual & School & Individual & School & Individual \\
\hline & Fixed & Fixed & Fixed & Fixed & Fixed & Fixed \\
\hline & Effects & Effects & Effects & Effects & Effects & Effects \\
\hline \multicolumn{7}{|l|}{ All } \\
\hline Network & 0.19 & -0.00 & 0.11 & 0.02 & -0.01 & 0.01 \\
\hline Average & $(4.64)$ & $(-0.07)$ & $(5.15)$ & $(1.34)$ & $(-1.25)$ & $(0.82)$ \\
\hline $\mathrm{R} 2$ & 0.1377 & 0.0279 & 0.0819 & 0.0000 & 0.0310 & 0.0148 \\
\hline NT & 7133 & 9863 & 7133 & 9863 & 7133 & 9863 \\
\hline \multicolumn{7}{|l|}{ Males } \\
\hline Network & 0.18 & - & 0.09 & - & -0.01 & - \\
\hline Average & $(3.62)$ & & $(3.42)$ & & $(-0.58)$ & \\
\hline $\mathrm{R} 2$ & 0.1462 & - & 0.0954 & - & 0.0642 & - \\
\hline NT & 3410 & - & 3410 & - & 3410 & - \\
\hline \multicolumn{7}{|l|}{ Females } \\
\hline Network & 0.19 & - & 0.12 & - & -0.02 & - \\
\hline Average & $(4.18)$ & & $(3.86)$ & & $(-1.63)$ & \\
\hline $\mathrm{R} 2$ & 0.1571 & - & 0.1117 & - & 0.0477 & - \\
\hline NT & 3723 & - & 3723 & - & 3723 & - \\
\hline
\end{tabular}

Robust t-statistics are reported in parentheses. All regressions include dummy variables for gender and grade. The regressions with school fixed effects also include controls for race and health status (broken into five dummy variables).

Table 4. Further Correlations Between Own Weight and Male and Female Peer Weight

\begin{tabular}{lcccc}
\hline \hline & \multicolumn{2}{c}{ BMI } & \multicolumn{2}{c}{ Overweight } \\
\hline & Male & $(2)$ & $(3)$ & $(4)$ \\
& 0.18 & Female & Male & Female \\
\hline $\begin{array}{l}\text { Male Network } \\
\text { Average }\end{array}$ & $(4.84)$ & $(6.54)$ & 0.17 & 0.13 \\
& & & & $(1.19)$ \\
Female Network & 0.14 & 0.30 & 0.18 & 0.17 \\
Average & $(4.68)$ & $(6.65)$ & $(3.10)$ & $(3.10)$ \\
& & & & \\
R2 & 0.1511 & 0.1598 & 0.1150 & 0.0953 \\
NT & 1109 & 1181 & 1109 & 1181 \\
\hline Robust t-statistics are reported in parentheses. All regressions include dummy variables for school and grade.
\end{tabular}


Table 5. Determinants of Changes in Own Weight

\begin{tabular}{llll}
\hline \hline \multicolumn{4}{l}{ Change in Own BMI } \\
\hline & $(1)$ & $(2)$ & $(3)$ \\
Average & All & Male & Female \\
Peer BMI & 0.038 & 0.023 & 0.061 \\
& $(1.73)$ & $(0.81)$ & $(2.05)$ \\
Change in Own & -0.496 & -0.434 & -0.609 \\
Height & $(-9.23)$ & $(-5.95)$ & $(-9.97)$ \\
Own BMI & -0.029 & -0.021 & -0.036 \\
& $(-2.53)$ & $(-1.39)$ & $(-1.97)$ \\
R2 & & & \\
N & 0.1940 & 0.2127 & 0.2550 \\
$\begin{array}{l}\text { All regressions include race, school, gender and age dummies as well as health status } \\
\text { (broken into five dummy variables and parental living arrangements. All standard } \\
\text { errors are clustered by school. Robust t-statistics are in parentheses. }\end{array}$
\end{tabular}


Table 6. The Impact of the Distribution of BMI in Peer Networks on Own BMI

\begin{tabular}{|c|c|c|c|c|}
\hline & \multicolumn{4}{|c|}{ Dependent Variable: Own BMI } \\
\hline & (1) & (2) & (3) & (4) \\
\hline $\begin{array}{l}\% \text { of Peer Group } \\
>=90^{\text {th }} \text { Percentile }\end{array}$ & $\begin{array}{l}1.25 \\
(4.27)\end{array}$ & - & - & - \\
\hline $\begin{array}{l}\% \text { of Peer Group } \\
>=85^{\text {th }} \text { Percentile }\end{array}$ & - & $\begin{array}{l}1.11 \\
(4.63)\end{array}$ & - & - \\
\hline $\begin{array}{l}\% \text { of Peer Group } \\
>=75^{\text {th }} \text { Percentile }\end{array}$ & - & - & $\begin{array}{l}1.03 \\
(5.12)\end{array}$ & - \\
\hline $\begin{array}{l}\% \text { of Peer Group } \\
<=10^{\text {th }} \text { Percentile }\end{array}$ & - & - & - & $\begin{array}{l}-0.00 \\
(-0.02)\end{array}$ \\
\hline $\mathrm{R} 2$ & 0.1235 & 0.1237 & 0.1243 & 0.1159 \\
\hline $\mathrm{N}$ & 7133 & 7133 & 7133 & 7133 \\
\hline
\end{tabular}

This table reports OLS results of regressions of BMI on the percentages of the individual's peer network who are above or below various thresholds. Robust t-statistics are in parentheses. All standard errors adjust for clustering by school. All regressions include controls for gender, race, health status (broken into five dummy variables) as well as a complete set of grade and school dummies.

Table 7. The Impact of the Distribution of BMI in Peer Networks on Own Overweight Propensity

\begin{tabular}{|c|c|c|c|c|}
\hline & \multicolumn{4}{|c|}{ Dependent Variable: Own Propensity to be Overweight } \\
\hline & (1) & (3) & (5) & $(7)$ \\
\hline $\begin{array}{l}\% \text { of Peer Group } \\
>=90^{\text {th }} \text { Percentile }\end{array}$ & $\begin{array}{l}0.11 \\
(5.15)\end{array}$ & - & - & - \\
\hline $\begin{array}{l}\% \text { of Peer Group } \\
>=85^{\text {th }} \text { Percentile }\end{array}$ & - & $\begin{array}{l}0.10 \\
(5.52)\end{array}$ & - & - \\
\hline $\begin{array}{l}\% \text { of Peer Group } \\
>=75^{\text {th }} \text { Percentile }\end{array}$ & - & - & $\begin{array}{l}0.09 \\
(5.50)\end{array}$ & - \\
\hline $\begin{array}{l}\% \text { of Peer Group } \\
<=10^{\text {th }} \text { Percentile }\end{array}$ & - & - & - & $\begin{array}{l}-0.00 \\
(-0.12)\end{array}$ \\
\hline $\mathrm{R} 2$ & 0.0819 & 0.0819 & 0.0825 & 0.0748 \\
\hline $\mathrm{N}$ & 7133 & 7133 & 7133 & 7133 \\
\hline
\end{tabular}


Appendix A. An Example of BMI Distributions for Children and Adolescents

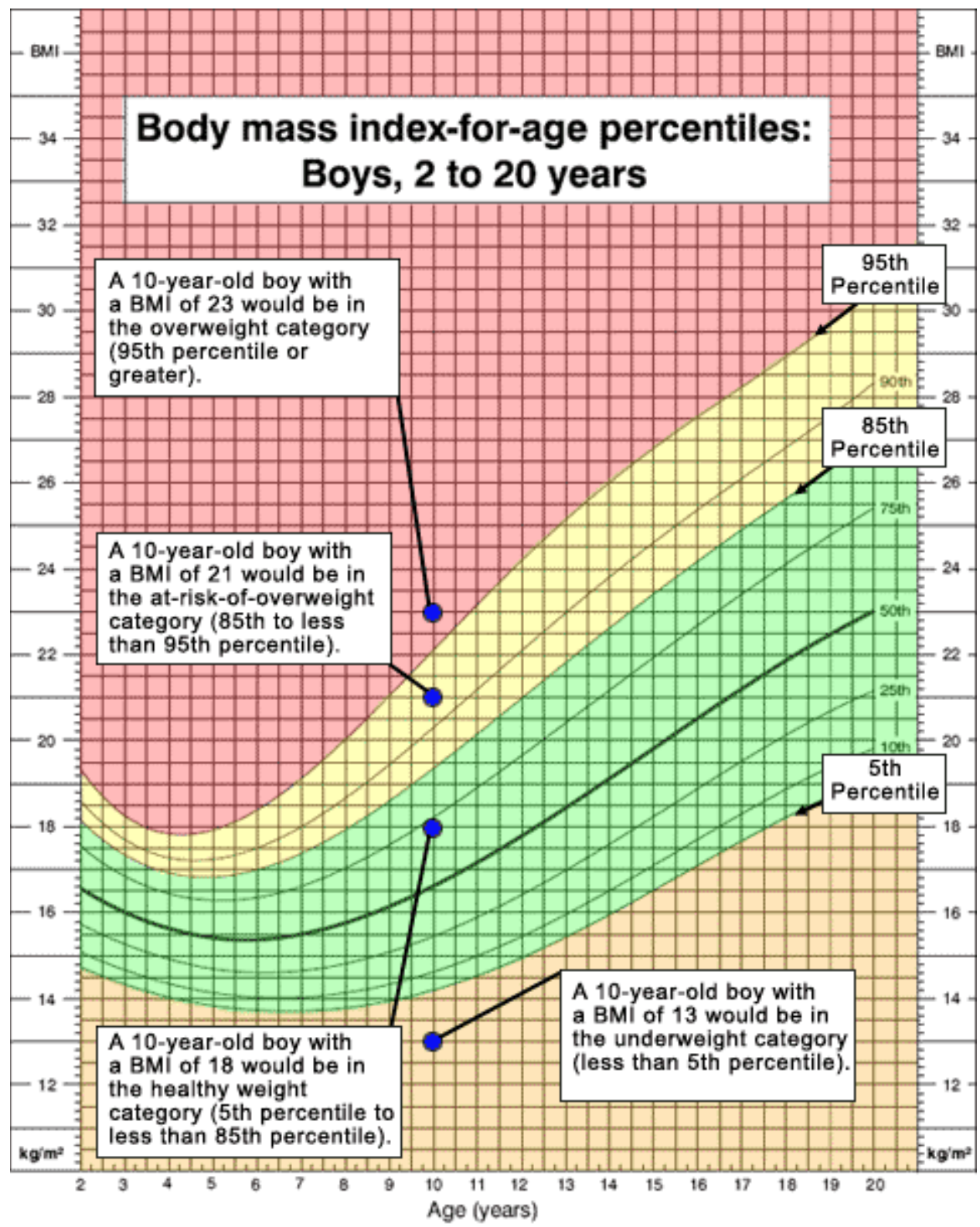

Reproduced from the CDC, Department of Health and Human Services website: http://www.cdc.gov/nccdphp/dnpa/bmi/childrens_BMI/about_childrens_BMI.htm 